\title{
Violência escolar - em xeque a proposta de cultura de paz no ensino médio
}

\author{
Checkmating the proposed peace culture in school in as a policy to \\ work with situations of violence
}

\author{
Flávia Cristina Silveira Lemos \\ Doutora em História e Mestre e Psicologia (UNESP). Professora nos programas \\ de pós-graduação em Educação e em Psicologia da Universidade Federal do Pará. \\ flaviacslemos@gmail.com
}

Dolores Cristina Gomes Galindo

Doutora e Mestre em Psicologia Social (PUC-SP). Professora no Programa de Pós-Graduação em Estudos de Cultura Contemporânea

da Universidade de Mato Grosso. dolorescristinagalindo@gmail.com

\begin{abstract}
Resumo
O presente artigo versa sobre a política denominada pela UNESCO de educação para uma cultura de paz, pela qual jovens pobres do Brasil são dirigidos a projetos e programas de esporte, teatro, dança, música, lazer e profissionalização, nos espaços da escola, mediados por organizações diversas. Utilizam-se as referências de Michel Foucault para interrogar as práticas derivadas dessa política e criticar o que este organismo denomina de educação para a paz como maneira de lidar com as situações de violência e prevenir futuras guerras, revoltas sociais e dissidências políticas. Por fim, tentamos propor uma prática agonística voltada a romper com os trajetos estabelecidos e questionamos a possibilidade de trabalhar esteticamente, pela escola e pela educação escolar, em caminhos éticos e políticos com jovens.

Palavras-chave: Educação e Ensino Médio. Esportes e Lazer. Jovens e Cultura. Pobreza. UNESCO e Paz.
\end{abstract}

\begin{abstract}
This paper discusses the practices of UNESCO called education for a culture of peace, in Brazil, where poor youth are directed to projects and programs in sports, theater, dance, music, leisure and professional spaces in the school, mediated by various organizations. Used references to Michel Foucault to question the practices of UNESCO on this young and criticize this body calls for peace education as a way to deal with situations of violence and preventing future wars, social upheavals and other political dissidents. Finally, we try to propose a practical agonistic courage to break with these paths established and we wonder if it is possible to work in the aesthetically ethical and political paths with young people in school and for school education.
\end{abstract}

Key words: Education and Secondary Education. Poverty. Sports and Leisure. UNESCO and Peace. Youth and Culture. 


\section{Introdução}

A Organização das Nações Unidas para a Educação, Ciência e Cultura (UNESCO) foi criada, em 1946, com a proposta de construir uma ordem mundial segura pela difusão de uma cultura que fomentasse a paz, preventivamente às guerras e às diversas situações de violência. Esse objetivo esteve relacionado às preocupações com os dois grandes conflitos mundiais da primeira metade do século XX e com os regimes totalitários que emergiram na época, nomeadamente o nazismo e o fascismo, além de guerras religiosas e civis que avassalaram várias regiões do globo, como se depreende dos excertos abaixo.

Desde 1948, a UNESCO vem acompanhando a evolução das agendas internacionais com uma missão específica: oferecer insumos concretos para a pacificação das relações internacionais. (UNESCO, 2002, p. 219)

A assembleia geral das nações unidas decidiu incumbir a UNESCO de levar a frente um movimento mundial de transição de uma cultura de guerra, de violência, de imposição e discriminação para uma cultura de não violência, de diálogo, tolerância e de solidariedade. Ou seja, à construção de uma cultura de paz. (op.cit., p. 171)

É de louvar a ideia de ensinar a não-violência na escola, mesmo que apenas constitua um instrumento, entre outros, para lutar contra os preconceitos geradores de conflitos. (UNESCO, 2006, p. 97)

Este artigo tem como propósito pensar as práticas concretas derivadas da proposta de cultura de paz da UNESCO da maneira como foram utilizadas no Brasil, em especial na sua relação com os jovens que frequentam o Ensino Médio e que passaram a ser vistos como preocupação social em razão de cálculos políticos de risco/perigo de se tornarem violentos e de causarem prejuízos à defesa e à segurança da população. Objetiva-se questionar as relações causais mecânicas que se estabelecem sobre o tema violência, na escola pública, vinculando-a diretamente à pobreza e à juventude; concomitantemente, propõe-se colocar em xeque os projetos esportivos e de arte que são dirigidos aos estudantes do Ensino Médio, nos 
fins de semana e nas madrugadas, nas quadras poliesportivas dos equipamentos escolares brasileiros em nome da promoção da cultura de paz.

É nesse contexto que, em meados da década dos anos 1990, a UNESCO decidiu concentrar seus esforços na temática da juventude que aparece, hoje, como o grande desafio para as políticas governamentais e para as escolhas realizadas pela iniciativa privada. (UNESCO, 2002, p. 220)

\section{Cultura de paz e as escolas brasileiras}

Projetos que oferecem esportes, lazer, cultura e artes aos jovens pobres têm sido chamados, no país, de Escola Aberta à Comunidade. "Não por acaso, portanto, o Programa Abrindo Espaços tem três focos: o jovem, a escola e a comunidade" (op.cit., p. 201), que pretende

Manter o jovem em atividades lúdico-recreativas é mantê-lo afastado das situações de risco e perigo. Mas além de preventivo, o Programa tem uma perspectiva transformadora ao pretender modificar as relações dos jovens com a escola, dos jovens com os próprios jovens e dos jovens com as comunidades onde vivem. (op.cit., p. 202)

De certa maneira, tais programas têm em comum a intenção de fomentar a designada cultura de paz propalada pela UNESCO em parceria com os ministérios da Educação, dos Transportes, da Justiça, da Cultura, dos Esportes, da Saúde e do Desenvolvimento Social, de forma mais intensiva na última década.

A UNESCO tem a convicção de que a cultura pode combater a pobreza, a ignorância e a violência. Basta construir os mecanismos adequados, os quais devem ser elaborados e implementados por todos. [...] Conceber a cultura como instrumento do desenvolvimento humano significa entendê-la como chave para a construção e a manutenção da paz, em cada esquina da América Latina. [.. . ]. (op.cit., p. 199) 
A tônica desses projetos envolve uma série de questões como a prevenção ao uso de drogas pelos jovens, o incentivo aos estudos e a diminuição das taxas de evasão e reprovação escolares; a busca por minimizar indicadores de letalidade entre os jovens estudantes moradores de bairros classificados como periféricos e por mobilizar a relação do estudante do Ensino Médio com a sua comunidade e família em direção ao aumento das taxas de escolarização de todos estes segmentos. Visam ainda a redução da violência como forma de socialização entre os alunos jovens e também romper com as situações de depredação do patrimônio das escolas, entre outros alvos de uma política articulada por organismos governamentais e não governamentais locais, regionais, nacionais e internacionais.

A ideia central do Programa é estimular a abertura das escolas nos fins de semana e disponibilizar espaços alternativos que possam atrair jovens. Essa estratégia resulta da observação de experiências bem-sucedidas, em vários países, onde o trabalho com jovens, nas dimensões artísticas, culturais e esportivas, constituiu excelente forma de prevenção à violência. (op.cit., p. 201)

A criação de grupos de dança, de música, de teatro e de esportes, e de atividades como gincanas e produção artesanal, podem, de acordo com a UNESCO, abrir nas escolas oportunidades para os jovens pobres se afastarem das drogas, dos furtos e da violência, assim como enfrentar o baixo desempenho nas atividades curriculares, estimular uma profissionalização mais qualificada e apoiar a redução da pobreza e das desigualdades de gênero, raça, etnia e de outras formas de discriminação social e econômica no Brasil atual.

Por outro lado, preciso estar alerta para a predominância do critério economicista na educação, que é uma tendência geral do processo de globalização. A educação de adultos não pode dissociar a mão de obra de uma visão humanista das relações sociais e econômicas. Não pode dissociar competência de cidadania. (op.cit., p. 16)

A UNESCO (op.cit., p. 236) ainda destaca que "a democratização das oportunidades de educação é indispensável para abrir oportunidades de crescimento 
para a juventude". E um dos desafios desse processo, para os assessores do organismo internacional, é a formação continuada dos docentes do Ensino Médio, em especial quanto ao foco em estratégias de criação de práticas de melhoria dos currículos dos cursos de formação de professores nos quesitos de promoção da equidade e de redução de discriminações sociais e econômicas no Brasil atual.

Em sociedades tão feridas pela pobreza, a política social é um ator estratégico do futuro. Se a sociedade em seu conjunto tem uma visão apropriada do papel que lhe cabe, e se há políticas adequadas, gerenciadas de forma efetiva, sua contribuição pode ser fundamental. Se, ao contrário, a visão é errônea e dá lugar a políticas limitadas e isoladas, a deterioração social continuará aumentando com grave risco de implosão. (UNESCO, 2008, p. 121)

Programas sociais como o Bolsa Escola fazem parte das estratégias de promoção da cultura de paz, pois vinculam a escolaridade à profissionalização, à oferta de arte, esportes e lazer associada ao fortalecimento de vínculos comunitários e familiares e à geração do que os trabalhadores sociais denominam renda básica, o que, potencialmente, resultaria no aumento de desempenho escolar de jovens matriculados no Ensino Médio. O Programa oferecido pelo Ministério do Desenvolvimento Social do Brasil é elogiado pelos assessores da UNESCO como dispositivo redutor da violência na vida dos jovens, incluída a cometida por eles. O dispositivo constitui:

[...] um conjunto decididamente heterogêneo que engloba discursos, instituições, organizações arquitetônicas, decisões regulamentares, leis, medidas administrativas, enunciados científicos, proposições filosóficas, morais, filantrópicas. Em suma, o dito e o não dito são os elementos do dispositivo. O dispositivo é a rede que se pode estabelecer entre estes elementos. (FOUCAULT, 1979, p. 244)

O Departamento Nacional de Trânsito (DENATRAN) também executa, na parceria com a UNESCO, outros programas: "Rumo à escola", "Educação e Segurança no Trânsito em Escolas do Ensino Médio" e "Mídia cidadã", com vistas a diminuir as situações de morte e violência ligadas aos acidentes de trânsito cometidos por jovens. Esses programas acontecem nas escolas de 
Ensino Médio brasileiras, "oferecendo consultoria e orientação educacionais para o desenvolvimento de atividades em sala de aula" (op.cit., p. 194), sob a justificativa de que

Falar em cultura de paz é falar dos valores essenciais à vida democrática, quais sejam: Participação; Igualdade, Respeito aos Direitos Humanos; Respeito da diversidade Cultural, Justiça, Liberdade, Tolerância, Diálogo, Reconciliação, Solidariedade, Desenvolvimento e Justiça Social. (op.cit., p. 175)

Ao falarmos dos valores essenciais à vida democrática, estamos falando dos valores ligados à cidadania em seu conceito mais amplo. Ser cidadão é participar na produção e no usufruto dos bens que uma sociedade produz, é ter acesso aos meios que uma sociedade produz, é ter acesso aos direitos humanos e sociais básicos, é ter seus direitos respeitados. (op.cit., p. 175)

No uso das táticas de comunicação para a cidadania, tanto no aspecto da educação de trânsito quanto no de aproximação dos jovens com a escola, a família e a comunidade, em prol da redução da violência e da construção da democracia participativa, a UNESCO vem articulando as relações entre agências de comunicação, Ministério da Comunicação e organizações governamentais e não governamentais com a proposta de criar redes de reciprocidade, solidariedade e humanismo nos marcos de uma política de educação para a paz. O objetivo principal é prevenir atos de envolvimento com o consumo e venda de drogas e outras formas de infração que venham a afastá-los da escolarização, da família e da comunidade a que pertencem.

Nesse sentido, jornais feitos por jovens nas escolas, apresentação de peças teatrais na televisão e de espetáculos de grupos musicais em rádios comunitárias com a participação da juventude, de associações de bairro e de professores são iniciativas que vêm ganhando popularidade com o fomento da UNESCO e de universidades, ONGs, fundações, institutos, projetos e programas brasileiros.

Os meios de comunicação têm a capacidade de despertar a discussão pública sobre o tema. Eles também são responsáveis para 
que a informação que circula pela sociedade observe os princípios dos direitos humanos e as diversas recomendações internacionais sobre o assunto. Desta maneira, governos nacionais, organismos internacionais, instituições financeiras, sociedade civil e meios de comunicação podem somar forças para propor soluções criativas - coerentes com os contextos domésticos - ao desafio da violência juvenil. (op.cit., p. 242)

A educação para a paz não é uma solução para o que se chama violência e prevenção de guerras, mas um modo de problematizar determinados acontecimentos e remetê-los a um conjunto de práticas sociais, econômicas, políticas, culturais, históricas, educativas, comunitárias, familiares e de jogos diplomáticos internacionais. Cabe desnaturalizar o que se chama de cultura de paz e colocar a paz na cifra da guerra, interrogar como em nome da paz são feitas batalhas e fomentados confrontos específicos que são lutas históricas de saberes e de poderes numa correlação de forças dinâmicas que atravessa as escolas, as comunidades e as famílias para além dos corpos dos jovens, ganhando materialidade na disputa entre as nações por medições de economia política, em contextos de liberalismo meritocrático.

Assim, a educação passou a ser um dispositivo em que as práticas internacionais realizam certa política da existência e, nesse passo, no âmbito dos equipamentos educativos, subjetivam estudantes, professores, orientadores e trabalhadores da escola com vistas a criar uma cultura de paz que não passa de uma tática de segurança e de defesa da sociedade utilitarista.

\section{Aportes de Foucault}

Os trabalhos e pesquisas de Michel Foucault (2008a) nos auxiliam a indagar a respeito dessas práticas de governamentalidade, de governar e ser governado, de constituir tramas e jogos de instauração de verdades no campo da política e, portanto, da vida da população, gerando uma economia calculada e administrada utilitariamente para gerar lucros e promover racionalidades de segurança.

Por essa palavra governamentalidade, eu quero dizer três coisas. Por governamentalidade, eu entendo o conjunto constituído 
pelas instituições, pelos procedimentos, análises e reflexões, pelos cálculos e pelas táticas que permitem exercer esse modelo bem específico, ainda que complexo, de poder, que tem por alvo principal a população, por modelo principal de saber a economia política, por instrumento técnico essencial os dispositivos de segurança. Em segundo lugar, por governamentalidade, eu entendo a tendência, a linha de força que, em todo o Ocidente, conduziu incessantemente, durante muito, muito tempo, à preeminência desse modelo de poder que se pode chamar de governo sobre todos os outros: soberania, disciplina etc. [...] enfim, por governamentalidade, eu acredito que seria preciso entender o processo, ou melhor, o resultado do processo pelo qual o Estado de justiça da Idade Média, que se tornou nos séculos XV e XVI Estado administrativo, como se viu pouco a pouco governamentalizado. (FOUCAULT, 1979, p. 277)

No Brasil, os professores do Ensino Médio podem ser transformados, com os estudantes e com outros trabalhadores, em corpos úteis, dóceis e disciplinados (FOUCAULT, 1999) pela escola e por outros equipamentos adestradores e agenciadores de vigilâncias, exames, controles dos corpos no tempo e no espaço, sanções normalizadoras e gestões mecânicas dessas tecnologias disciplinares em nome da cultura de paz. Referimo-nos às liberdades reguladas, no plano do neoliberalismo, pelo entrecruzamento da economia política com os direitos humanos, sob a soberania jurídica do Estado Democrático de Direito atual e a batuta da UNESCO e de seus chamados parceiros.

Foucault (2008b) já havia analisado como a noção de paz foi evocada para tratar da guerra e da violência e como o contrato social não era suficiente para evitar violências, já que os direitos não iam acabar com as disputas, apenas lhes provia um enquadramento jurídico de lei, norma e sangue, por conta das práticas racistas em jogo na defesa da sociedade contemporânea.

Com efeito, que é o racismo? É, primeiro, o meio de introduzir afinal, nesse domínio da vida de que o poder se incumbiu, um corte: o corte entre o que deve viver e o que deve morrer. No contínuo biológico da espécie humana, o aparecimento das raças, a distinção das raças, a hierarquia das raças, a qualifi- 
cação de certas raças como boas e de outras, ao contrário, como inferiores, tudo isso vai ser uma maneira de fragmentar esse campo do biológico de que o poder se incumbiu; uma maneira de defasar, no interior da população, uns grupos em relação aos outros. (FOUCAULT, 1999, p. 304)

Desse modo, podemos interrogar os projetos e programas que no Brasil são financiados e/ou assessorados pela UNESCO quanto a seus efeitos na vida dos jovens e nos espaços escolares do Ensino Médio. Podemos perguntar como a guerra opera na cifra da paz nesses espaços e o que essas batalhas produzem. Também podemos nos perguntar, no caso da formação dos professores e dos currículos pautados em tais projetos e programas, sobre a forma como constituem determinadas subjetividades denominadas de pacificadas e como as engendram como tal.

A disciplinarização dos corpos por meio de atividades esportivas e artísticas, de lazer e cultura, de educação e profissionalização pode ser uma prática de enquadramento subjetivo e lucrativo em tempos de sociedades neoliberais que visam tornar a escola um espaço de geração de renda e de juventudes obedientes e produtivas. Essas atividades, de maneira geral, têm sido ligadas às práticas disciplinares pelo Estado governamentalizado tanto em instituições quanto em meio aberto, em projetos voltados para jovens como oficinas culturais em praças, quadras poliesportivas, ginásios, ruas, escolas e clubes.

A disciplina às vezes exige a cerca [. . . . A fábrica parece claramente um convento, uma fortaleza, uma cidade fechada. [. . .] Mas o princípio de clausura não é constante, nem indispensável, nem suficiente nos aparelhos disciplinares. Estes trabalham o espaço de maneira muito mais flexível e mais fina. [...] Ela individualiza os corpos por uma localização que não os implanta, mas os distribui e os faz circular numa rede de relações. (FOUCAULT, 1999, p. 123-125)

Vale destacar que repartir os corpos de jovens em espaços específicos e regular sua circulação em determinados tempos e lugares, com o uso da cultura da paz e em nome de sua promoção, é uma forma de forjar docilidade política pelo uso intensivo de mecanismos disciplinares e de vigilância social. Separar e filtrar as multidões para evitar revoltas e dissidências tem sido uma estratégia de controle 
social e econômico utilitarista que tem na UNESCO e em diversos organismos de fomento, sob a capa de instituições e projetos bem intencionados e do baluartismo da democracia regulada.

A vinculação determinista entre juventude e violência também é algo que deve ser questionado e pensado pela escola e pelos professores do Ensino Médio, em vez de ser aceita em nome da obediência às prescrições da UNESCO e de seus promotores no Brasil atual. Ora, mas de que modo docentes e escolas, jovens, comunidades e famílias podem colocar em xeque as receitas da UNESCO e dos aparatos governamentais brasileiros?

Para Foucault (1979), as relações de poder, saber e subjetivação são dinâmicas, móveis, microfísicas; perpassam os corpos em exercícios permanentes e regulares de assujeitamento e de táticas de expansão de habilidades, cognições, produtividade e capitalização/administração técnica do tempo. O mesmo autor analisou que onde há relações de poder-saber há resistência, como um diagrama entrecruzado de agenciamentos de forças em relação constante e mutação simultânea de regimes de visibilidade e de dizibilidade, compondo mapas provisórios em que nos situamos como subjetividades que não se colam nas tentativas de especialistas de projetos que buscam nos controla

\section{Novas questões para não concluir}

Resistir em meio às tentativas de captura e cooptação implica dobrar as forças de outras maneiras, deslocá-las em meio às batalhas experimentadas, produzindo liberdade no mesmo instante em que efetuam mecânicas de controle dos nossos corpos. Os mesmos mecanismos constituiriam dispositivos de resistência a ser utilizados como deslocamento de forças entre os corpos e, nos entremeios da política afirmativa da vida, um meio de fazer da arte, dos esportes, da cultura, da literatura e do lazer estratégias de uma estilística da existência que inquieta e move territórios disciplinares para a dispersão do imprevisível e da subjetivação que não obedecem a cartilhas de organismos e ministérios, muito menos de bancos e agência econômicas securitárias?

Como pensar, por exemplo, a arte como um dispositivo em um plano estético, imanente ao ético e ao político, a partir de experiências que poderiam ser definidas como uma clínica em nome da vida, da afirmação da vida? Mas que vida? Uma vida 
não fascista, produzida nos encontros entre os corpos e no acolhimento da diferença em meio às aberturas que são tecidas, nas bifurcações que são tramadas, nos ensaios e experimentações efetuados a partir do plano dos afetos e intensidades.

Arte enquanto estética implica estabelecer encontros sem cartilhas e sem rumos prévios a alcançar, pois só poderemos falar dos encontros a partir de uma ética da experimentação e não por uma medida ou valor anterior ao encontro. Assim, propor uma ética - e não uma moral - para os jovens poderia ser uma prática de não enquadrar subjetividades em crivos prévios e também de não normalizar corpos, muito menos ditar regras ou impor modelos prontos e acabados; poderia, sim, ser uma prática que buscar criar territórios porosos, criar tensões no que está cristalizado, abrir janelas, interrogar o que parecia dado, constituir campos de possíveis, tentando fazer a vida pulsar.

A noção de arte só interessa como estética da existência, pois é na criação de maneiras de pensar e agir que a mesma se torna um disparador e um mecanismo de formulação de perguntas, e não de respostas, que se dão em meio aos agenciamentos e composições imprevisíveis significa abandonar as cartilhas prontas. Nesse sentido, tratamos de um jogo gerador de acontecimentos insólitos; falamos da instalação de um exercício de criação de paisagens em que se possa morar e habitar provisoriamente, sem colar-se ou colar os corpos em quadros idealizados. Trata-se de confeccionar um campo de ações disruptivas com os traçados padronizados, a partir de uma estratégia de intensificação de perguntas-problemas que não eram receitas e técnicas de modelagem, mas fuga à modelagem e às receitas e um convite à invenção constante. Propomos fazer da vida não uma cultura de paz, mas uma produção de forças que nos faça sonhar e rachar universos dados, supostamente naturais, e nos descolarmos de formas prontas para viver, sentir, pensar e agir, instituindo outros caminhos que não estão em relatórios de organismos multilaterais.

Ir ao cinema, pegar o ônibus, atravessar a rua, observar as placas, pedir algo na lanchonete, pagar o salgado e o suco degustado, folhear as revistas e gibis nas bancas, sentar na praça, entrar no parque e no circo, visitar um museu, conhecer a universidade... experiências de cidadania das quais muitos jovens são e foram excluídos e privados pela administração tutelar é uma aventura de estranhamento da cultura de paz e da educação disciplinadora.

Como nomadizar na cidade, sem eira nem beira, sem mapa nem guia, sem roteiro e rotina, sem dizer para onde quer ir e ninguém dizer a você para onde ir? Estética, ética e política? 
Nesse aspecto, vale à pena perguntar do que se é capaz, deslocar as questões e as respostas, pois ensinar é mover. Como agente cultural, fazer a existência conjuntamente com as escolhas políticas. Perturbar o que parece inerte e cristalizado. Rever o que passou e o que foi feito. Exercitar a confiança e a reciprocidade na amizade filosófica, em uma rede de trocas sociais e de sabedoria, e jamais perder-se de vista. (FOUCAULT, 2010)

\section{Referências}

FOUCAULT, M. Microfísica do poder. Rio de Janeiro: Graal, 1979. . Vigiar e Punir: história do nascimento da prisão. $3^{\text {a }}$ ed. Petrópolis: Vozes, 1999a. . O sujeito e o poder. In: DREYFUS, H. \& RABINOW, P. Michel Foucault, uma trajetória filosófica: para além do estruturalismo e da hermenêutica. Rio de Janeiro: Forense Universitária, 1995. .Em defesa da sociedade. São Paulo: Martins Fontes, 1999.b . Segurança, território e população. São Paulo: Martins Fontes, 2008a. Nascimento da Biopolítica. São Paulo: Martins Fontes, 2008b. . A Hermenêutica do Sujeito. São Paulo: Martins Fontes, 2010.

UNESCO. Nossa diversidade criadora: Relatório da Comissão Mundial de Cultura e Desenvolvimento. Campinas/SP: Papirus - Brasília: UNESCO, 1997.

. Construção e identidade: as ideias da UNESCO no Brasil. Brasília: Jorge Werthein/UNESCO, 2002.

Por uma economia com face mais humana. Brasília: UNESCO, 2003.

Relatório Jacques Delors. Educação para o século XXI: um tesouro a descobrir. Brasília: Cortez/MEC/UNESCO, 2006.

. Mais ética, mais desenvolvimento. Brasília: UNESCO, 2008.

REVEL, J. Foucault: conceitos essenciais. São Carlos/SP: Claraluz, 2005.

recebido em 21 set. 2012 / aprovado em 20 nov. 2012

Para referenciar este texto:

LEMOS, F. C. S.; GALINDO, D. C. G. Violência escolar - em xeque a proposta de cultura de paz no ensino médio. Dialogia, São Paulo, n. 16, p. 129-140, 2012. 